\title{
A Avaliação do uso de Objetos de Aprendizagem na Educação de Jovens e Adultos
}

Title: Assessment of Learning Objects use for Young and Adults Education

Kethure Aline Oliveira

Universidade Estadual do Norte do

Paraná - Campus Luiz Meneghel

kethureoliveira@gmail.com

\author{
Marília Abrahão Amaral \\ Universidade Tecnológica Federal do \\ Paraná \\ marilia.utfpr@gmail.com
}

\author{
Gabriela Recipputi Domingos \\ Universidade Estadual do Norte do \\ Paraná \\ gabi_reciputti@hotmail.com
}

\begin{abstract}
Resumo A introdução de softwares educacionais nas escolas públicas do Brasil é uma prática que vem ganhando destaque no âmbito educacional. Sob essa perspectiva, diversas ferramentas dão apoio à aprendizagem, uma delas são os Objetos de Aprendizagem, definidos como qualquer recurso digital que pode ser reutilizado para promover a aprendizagem. A presente pesquisa pretende analisar a satisfação do usuário com o uso de Objetos de Aprendizagem como forma de ferramenta de apoio no processo ensino-aprendizagem da Educação de Jovens e Adultos. Os dados coletados indicam aspectos positivos na utilização dessa ferramenta em níveis de ensino distintos, confirmando assim a possibilidade de reutilização da ferramenta para apoiar a aprendizagem de públicos distintos em situações e disciplinas curriculares diferentes.
\end{abstract}

Palavras-Chave: Informática, Software Educacional, Reutilização, Objetos de Aprendizagem, Educação de Jovens e Adultos.

\begin{abstract}
The introduction of educational software in Brazilian public schools is a practice that has come to prominence in the educational field. From this perspective, several tools support the learning, some of them are learning objects, defined as any digital resource that can be reused to promote learning. The purpose of this study was to evaluate user satisfaction with the re-use of learning objects as a tool to help in the teaching-learning of Youth and Adults. The data collected indicate positive aspects in the use of this tool in different educational levels, thus confirming the possibility of reusing of the tool to support learning of different audiences in different situations and different courses.
\end{abstract}

Keywords: Informatics, Educational Software, Reuse, Learning Objects, Education of Youth and Adults. 


\section{Introdução}

A utilização da tecnologia aliada à educação vem se tornando um auxílio para a aprendizagem, incluindo digitalmente alunos na sociedade e motivando-os para a busca do conhecimento. De acordo com [1], o computador pode provocar uma mudança no paradigma pedagógico, sendo usado na educação como máquina de ensinar ou como ferramenta. $\mathrm{O}$ uso do computador como máquina de ensinar consiste na informatização de métodos de ensino tradicionais.

O uso do computador aliado ao quadro negro, giz e livro didático, juntamente com as metodologias de ensinoaprendizagem e os professores, tem facilitado a aceleração do processo de ensino-aprendizagem, proporcionando aos alunos interação com o conteúdo, através de animações, visualizações e verificações disponíveis durante a utilização desses softwares educativos.

Um exemplo relevante de softwares educativos são os Objetos de Aprendizagem (OAs), que podem ser definidos como quaisquer entidades, digital ou não, que podem ser aplicadas no âmbito da aprendizagem, educação ou treinamento [2].

Documentos como os Parâmetros Curriculares Nacionais - PCN [3], defendem a utilização da tecnologia nas escolas. Essas recomendações também são feitas em políticas governamentais, tais como: Programa Nacional de Informática Educativa - PROINFO [4], Rede Interativa Virtual de Educação - RIVED [5], Um Computador por Aluno - UCA [6], Banco Internacional de Objetos Educacionais, dentre outras.

Por exemplo, o Banco Internacional de Objetos Educacionais é um repositório que possui OAs de acesso público, em vários formatos e para todos os níveis de ensino. Os objetos podem ser acessados isoladamente ou em coleções. Esta iniciativa promove o acesso gratuito aos conteúdos [7].

Tendo em vista a crescente utilização de softwares educacionais aliados a educação, este trabalho propõe a reutilização de Objetos de Aprendizagem como ferramenta pedagógica para apoiar o processo de ensinoaprendizagem na modalidade de Educação de Jovens e Adultos (EJA).

Os OAs foram desenvolvidos pelo Grupo de Informática na Educação (GIED), da Universidade Estadual do Norte do Paraná, para um público alvo específico - alunos da $5^{\mathrm{a}}$ série do Ensino Fundamental - entretanto, devido ao fato de Objetos de Aprendizagem serem caracterizados, principalmente, pela flexibilidade na reutilização
[2], foram aplicados em um público alvo diferenciado, a EJA. Vale ressaltar que o processo de aplicação foi acompanhado por professores que já trabalham com a EJA. Nesta ocasião os OAs foram analisados pelos docentes da modalidade EJA, que não consideraram relevantes alterações nos conteúdos, linguagem, atividades e telas dos objetos, já que as ilustrações, textos e atividades adotadas não comprometem a reutilização dos OAs.

A modalidade EJA integra alunos que não tiveram oportunidades ou acesso a escolaridade e hoje preiteiam o direito ao conhecimento e a uma possível ascensão social, demais conceitos que caracterizam essa modalidade são esclarecidos na seção 2.

\section{A Educação de Jovens e Adultos}

Segundo [8] a história da Educação de Jovens e Adultos é amparada por lei, voltada para pessoas que não tiveram acesso, por algum motivo em específico, ao ensino regular na idade adequada.

A história da modalidade EJA apresenta muitas variações ao longo dos anos, evidenciando estarem diretamente ligadas as transformações sociais, econômicas e políticas que caracterizaram os diversos momentos históricos do Brasil [8], [9], [10], [11].

Ao longo dos anos, até os dias atuais, a EJA vem ganhando destaque como ferramenta de erradicação do analfabetismo já que essa é uma prioridade a ser alcançada.

A Constituição Federal determina, como um dos alvos do Plano Nacional de Educação, a integração de ações que erradiquem o analfabetismo. Entretanto, o número de indivíduos analfabetos ainda é alto, atingindo 16 milhões de brasileiros maiores de 15 anos, entre outros milhares que cursaram apenas de 1 a 3 anos da escola, os chamados analfabetos funcionais [12].

De acordo com [13], a EJA destina-se a assegurar gratuitamente aos jovens e adultos, que não puderam efetuar os estudos na idade regular, oportunidades educacionais apropriadas, considerando as características do aluno, seus interesses, condições de vida e de trabalho. Sendo de responsabilidade do poder público viabilizar e estimular o acesso e a permanência do trabalhador na escola, mediante ações integradas e complementares entre si.

$\mathrm{Na}$ opinião de [14] refletir sobre como estes jovens e adultos pensam e aprendem envolve transitar por três campos que contribuem para a definição de seu lugar social: (1) A condição de adulo; (2) A condição de excluído da escola e (3) A condição de membros de um determinado grupo social. Em relação à primeira condição 
esbarramos com a primeira dificuldade, a falta de estudos e pesquisas a respeito das teorias do desenvolvimento dos adultos [15], [16].

O uso de softwares educativos nessa modalidade servirá como ferramenta auxiliadora para almejar as três funções básicas destinadas a essa modalidade.

Os alunos, por intermédio de softwares, terão novas ferramentas para apoiar a resolução de problemas e, concomitantemente, motivação para aprender [17].

De acordo com [17] o computador constitui uma ferramenta fundamental dentre as tecnologias, participando diretamente de processos que envolvem novas abordagens de ensino-aprendizagem por intermédio de ambientes informatizados. Levar os alunos da EJA aos laboratórios de informática, com acessos a softwares educacionais como ferramentas pedagógicas é incluir a valorização dos alunos perante a sociedade.

O uso da tecnologia pode facilitar a aceleração do processo ensino-aprendizagem, com a possibilidade de propiciar melhor desempenho dos alunos, complementando alguns conteúdos que são de difícil exposição no método tradicional.

Várias pesquisas, [8],[9], [11], [13], [14], demonstram que a garantia da educação de qualidade para jovens e adultos permite a valorização do estudo, mesmo que em faixa etária mais avançada.

De acordo com [18] os motivos que levam esses jovens e adultos à escola, apresentam, predominantemente, alcançar o objetivo principal de conseguir um emprego melhor. Mas suas motivações também incluem vontade em entender os fatos, expressar-se mais claramente e ser independente [19], [20].

Para [21] a efetiva participação de homens e mulheres em cada esfera da vida é requisito fundamental para a humanidade sobreviver e enfrentar os desafios do futuro. Sendo assim, a EJA, dentro desse contexto, torna-se mais que um direito: é a chave para o século XXI, é tanto consequência do exercício da cidadania como condição para uma plena participação na sociedade

Motivar esses alunos a frequentarem a escola pode ser a chave para que se sintam encorajados a aprenderem e assim diminuir a evasão escolar, possibilitando uma mudança social.

Vale salientar que o computador obedece ao ritmo próprio do aluno, permitindo que atividades sejam refeitas quantas vezes forem necessários. Destaca-se ainda, o fator prontidão com que o aluno recebe o feedback as suas interações. Considerando assim, um instrumento ideal para a motivação. Acredita-se que o computador seja o instrumento contribuidor, efetivo, para a superação das dificuldades na aprendizagem do aluno da EJA, auxiliando na melhoria da qualificação para o meio social [18].

Segundo [18] uma prática pedagógica na EJA que faça uso de softwares educacionais é uma solução criativa, pois permite que o aluno, através do computador, desenvolva a capacidade de manusear essa máquina, tornandose, ao mesmo tempo, melhor qualificado para o mercado de trabalho.

O uso de softwares aliados a educação é uma ferramenta que colabora no processo de aprendizagem dos alunos auxiliando o professor, como é demonstrado na seção 3 enfatizando a informática na EJA.

\section{Informática na Educação e EJA}

A habilidade mais importante na determinação do padrão de vida de uma pessoa tornou-se a capacidade de aprender novas habilidades, de assimilar novos conceitos, de avaliar novas situações e de lidar com o inesperado [22].

Segundo [23] essa abordagem nos mostra de forma clara, que o computador pode ser um grande aliado, não só, para garantir o sucesso no século XXI, como também para o desenvolvimento das próprias habilidades do ser humano de acordo com os seus potenciais biopsicológicos.

Ainda segundo [22] as tecnologias vão reencantar a educação e que elas estão provocando profundas mudanças em todas as dimensões de nossas vidas. No entanto não são as tecnologias que estão mudando nossas vidas, mas, os usos múltiplos e diferenciados que estamos fazendo delas.

O computador está proporcionando uma verdadeira revolução no processo de ensino-aprendizagem. Uma das razões dessa revolução é o fato de ele ser capaz de ensinar. Não existe uma única maneira de utilizar o computador na educação [1].

De acordo com [24], a informática pode ser inserida nas escolas de três formas: informática como fim, que prevalece o enfoque técnico, informática como apoio para as atuais disciplinas existentes, que é quando o educador utiliza o computador apenas para complementar o processo educacional, ou para projetos educacionais, utilizando de recursos de informática para transmitir o conteúdo, prevalecendo a visão integrada e sistêmica. Como no caso exposto neste artigo.

\subsection{Objetos de Aprendizagem}

A utilização de tecnologias nas escolas auxilia no processo de ensino-aprendizagem, favorecendo a 
representação e comunicação do pensamento, resolução de problemas e desenvolvimento de projetos [25]. Por esses motivos, é cada vez maior a produção e disponibilização de materiais digitais tais como, imagens, vídeos, gráficos e jogos educacionais para apoiar professores e alunos nas atividades escolares.

Dentre as conceituações para Objetos de Aprendizagem, [26], os define como qualquer recurso digital - imagens, gráficos, vídeos entre outros - que pode ser reutilizado para promover a aprendizagem.

Por sua vez, [27] vai mais longe e define os OAs como Objetos de comunicação utilizados para fins instrucionais podendo ser interativo ou não.

Segundo [25], os Objetos de Aprendizagem são recursos didáticos interativos e possibilitam a utilização de recursos visuais para explicar determinado assunto. Podese utilizá-los para simulações e experiências práticas, estimulando a vivência de situações e a solução de problemas de um determinado conteúdo em que o aluno só teria contato teórico, como visto na Figura 1, na qual o aluno pode observar as estrelas citadas pela personagem do OA.

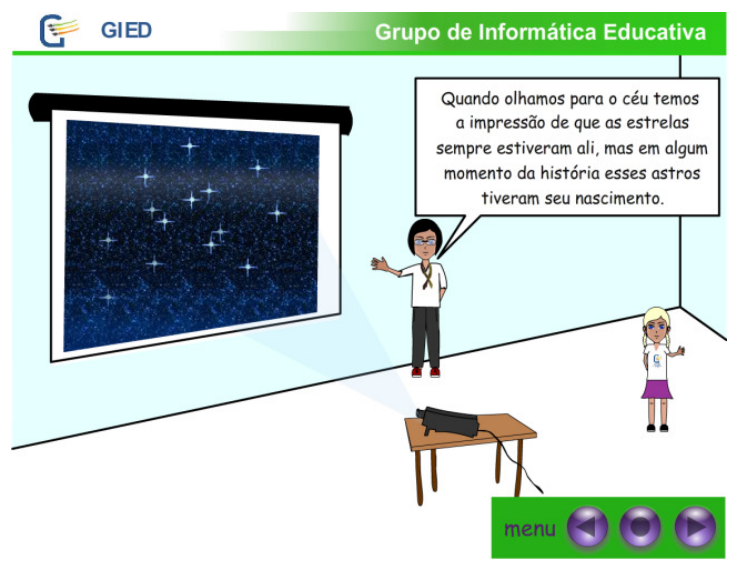

Figura 1: Tela OA de Astronomia

De acordo com [28] os Objetos de aprendizagem possuem várias características marcantes, como, interoperabilidade, granularidade, acessibilidade e reusabilidade. Estas características são mais bem detalhadas por [26] da seguinte forma:

- Interoperabilidade: Em síntese trata-se da possibilidade de utilização em diferentes sistemas operacionais e até em diferentes navegadores, quando o OA é utilizado na web.
- Reusabilidade: Baseia-se em informações, que descrevem e catalogam os conteúdos contidos no Objeto, com isso pode-se buscar, acessar e utilizá-lo em disciplinas diferentes, mas com conteúdos que tenham similaridade.

- Acessibilidade: É a característica que torna o OA fácil de ser utilizado em diferentes dispositivos, softwares e ambientes computacionais. Também vale destacar que o OA deve ser acessível não só por portadores de necessidades especiais, mas também pelos usuários em geral.

- Granularidade: Definição do tamanho ideal para o Objeto de Aprendizagem.

Estas características também são defendidas por [29] que dá ênfase especial na importância da reusabilidade em Objetos Educacionais. A autora ressalta a importância de os OAs serem construídos de tal forma que eles possam ser utilizados em aplicações diversas.

Os OAs aqui apresentados não foram desenvolvidos especificamente para essa pesquisa, pelo contrário, foram desenvolvidos com o intuito de apoiar a aprendizagem de alunos do ensino fundamental.

Nesse caso a reusabilidade se mostra no fato de, apesar de terem sido desenvolvidos para alunos do Ensino Fundamental, os objetos puderam ser utilizados em aplicações com alunos da EJA.

Outra característica desses Objetos é a interoperabilidade, já que eles não estão vinculados a nenhuma plataforma específica, garantindo a democratização da informação por não haver restrição ao seu acesso.

\subsection{Objetos de Aprendizagem na EJA}

Dentre os recursos explorados na educação de Jovens e Adultos, pode-se considerar que a Informática Educativa preenche as funções básicas garantidas por incisos da lei [13], uma vez que colabora para o aumento da qualidade do ensino na escola, ajuda a aumentar a diversificação do modo de aprendizagem e ajuda a formação profissional do aluno.

Os benefícios da Informática na EJA podem ser vistos em outros trabalhos, como, por exemplo, no projeto Construindo a Cidadania, onde a autora [19] descreve os benefícios do uso do computador na Educação de Jovens e Adultos.

Em seu artigo, Vasconcelos [31], também faz uma análise, sob a ótica docente, da utilização de Objetos de Aprendizagem, concluindo que é uma ótima opção para professores da EJA contribuindo no processo de ensinoaprendizagem e proporcionando ao professor o acompa- 
nhamento do desenvolvimento de seus alunos. No intuito de utilizar a informática como apoio para as atuais disciplinas existentes pode-se utilizar os Objetos de Aprendizagem, que deverão ser construídos de forma a serem utilizados independente de plataforma ou publico escolhido.

\section{Proposta da Pesquisa}

O desenvolvimento dessa pesquisa tem o intuito de avaliar a satisfação e por consequência a motivação de alunos da EJA na utilização de ferramentas que apoiem a diversificaçãodas aulas convencionais. Desta forma, a pesquisa foi definida como pesquisa aplicada já que objetivou adquirir conhecimentos e aplicá-los na solução de problemas práticos. Esta pesquisa ainda pode ser classificada como pesquisa prática, com objetivo exploratório e descritivo e abordagem qualitativa.

Segundo [32], [33], os métodos de avaliação são divididos em três subcategorias, avaliação preditivo-analítica, objetiva/empírica e prospectiva. A primeira subcategoria não necessita da participação do usuário e não é exigido o uso do software em uma situação real. A avaliação objetiva/empírica pressupõe a participação ativa do usuário, com sessões de observação da interação. E por fim, a técnica prospectiva é caracterizada principalmente por exigir a presença do usuário, emitindo suas contribuições com suas experiências, opiniões e preferências. Baseiamse nas aplicações de questionários que relatarão a satisfação ou insatisfação dos usuários ao utilizarem o software [34].

Nesta pesquisa a avaliação adotada foi a prospectiva baseada na aplicação de um questionário para medir a satisfação dos usuários na utilização do Objeto de Aprendizagem. Segundo [35], o sucesso das técnicas prospectivas depende da objetividade do instrumento de coleta adotado, quanto mais dirigido para os dados a serem analisados e menos ambíguo, melhor será a eficácia do instrumento.

Buscando avaliar as possibilidades de reutilização de Objetos de Aprendizagem, os OAs foram utilizados em modalidades diferentes as do público alvo inicialmente focado no seu desenvolvimento ( $5^{\mathrm{a}}$ série do Ensino Fundamental).

A pesquisa foi realizada em aulas no laboratório de informática, em uma escola pública da rede municipal de Bandeirantes - PR. A coleta de dados foi desempenhada durante a aplicação dos OAs no laboratório de informática da escola, através de questionários direcionados aos alunos.

Os dados obtidos por meio dos questionários foram agregados às observações realizadas durante a aplicação e, então foram tabulados para que nesta seção serem apresentados em conjunto de informações com as considerações dos alunos referentes ao ensino do conteúdo mediado pelos Objetos de Aprendizagem.

Os Objetos de Aprendizagem aplicados dividem-se em dois grupos: (1) OAs de conteúdos escolares, destinados ao ensino de conteúdos curriculares das disciplinas de matemática e ciências do Ensino Fundamental; (2) OAs de inclusão digital, dedicados ao ensino de conceitos de informática básica.

Foram aplicados 4 OAs em 5 turmas da modalidade EJA do Colégio Estadual do Paraná. Os resultados obtidos serão discutidos na próxima seção.

\section{Resultados}

Para o processo de coleta de dados, a condição adotada foi composta por um total de 75 alunos da EJA divididos em 5 turmas distintas. A primeira delas contando com 12 alunos, a segunda com 18 alunos, a terceira com 17 alunos, a quarta turma com mais 19 alunos e por fim a quinta turma contida de 9 alunos.

As aplicações foram realizadas no laboratório de informática do próprio Colégio Estadual do município em que os alunos estudam.

A primeira turma, contendo 12 alunos, utilizou o OA "Adição e Subtração" durante um período de aproximadamente 80 minutos, a segunda turma contou com a presença de 18 alunos que utilizaram o OA "Atmosfera" durante um período de 75 minutos, enquanto que a terceira e a quarta turma tiveram a participação de 17 e 19 alunos respectivamente, que utilizaram o OA "Introdução à Informática: Mouse" durante 60 e 70 minutos concomitantemente.

Já a última turma utilizou durante 100 minutos o Objeto intitulado "Frações".

É relevante ressaltar que os Objetos de Aprendizagem em questão não são apenas focados no ensino de disciplinas escolares, mas também em aprendizagem inclusiva, dando margem a inclusão social dos alunos da EJA.

Na tabulação dos dados obtidos na aplicação do Objeto de inclusão digital "Introdução à Informática: Mouse" pode-se encontrar telas que ressaltaram um maior interesse dos alunos, destacam-se as telas da atividade "Palavra Cruzada" (Figura 2) e "Forca" (Figura 3). 


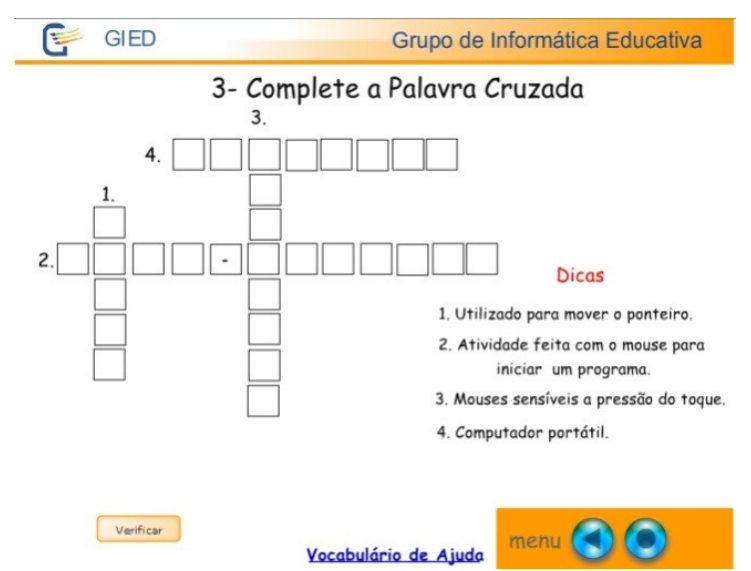

Figura 2: Atividade Palavra Cruzada

A segunda tela com maior índice de interesse dos alunos foi a atividade "Forca" (Figura 3).

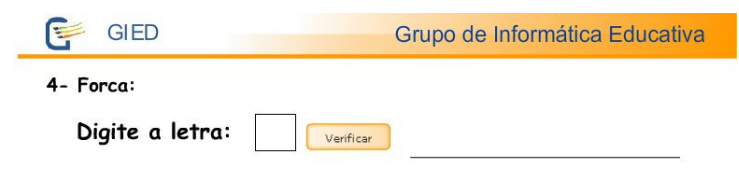

Mouse utilizado no Notebook:

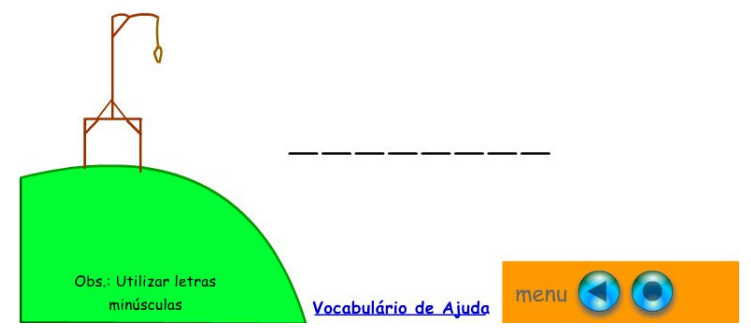

Figura 3: Atividade Forca

A seguinte questão foi indagada no intuito de medir qual tela despertava maior interesse dos usuários: "Qual animação ou vídeo foi mais interessante?". É possível observar os interesses na Figura 4.

\section{Animações interessantes}

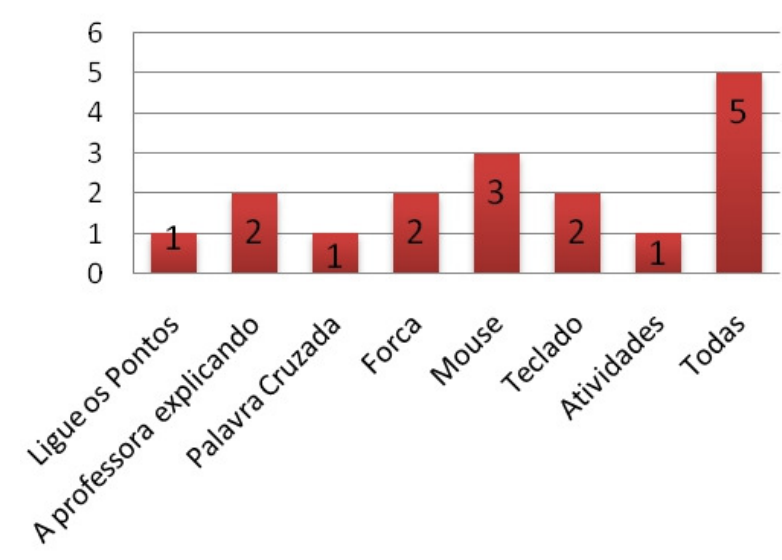

Figura 4: Gráfico das animações interessantes

A aplicação do Objeto de Aprendizagem "Frações" foi realizada em um público-alvo de 9 alunos com faixa etária entre 18 e 56 anos, durando cerca de 100 minutos.

Esse OA foi desenvolvido considerando os padrões apresentados na seção 3.1, o público-alvo demarcado na inicialização de seu desenvolvimento foi a $5^{\text {a }}$ série do Ensino Fundamental, seu conteúdo é destinado ao ensino introdutório de frações, na disciplina de matemática.

A aplicação foi realizada com o intuito de reforçar o conteúdo curricular da disciplina de matemática, frações, tendo em vista que esse conteúdo já havia sido apresentado pela professora em aulas convencionais (aulas abordadas pelo professor com o auxilio do quadro negro, livro didático e giz). Além disso, esperou-se enfatizar a reutilização de Objetos de Aprendizagem em públicos alvos distintos, pois o OA "Frações" foi aplicado na modalidade EJA.

Ao término da aula no laboratório de informática foi possível colher dados relatados pelos alunos ao responderem o questionário aplicado, dentre as perguntas pertinentes a aplicação, destacam-se algumas que enfatizam o uso do computador aliado a educação como ferramenta motriz para instigar o interesse do aluno sobre um conteúdo específico.

Na Figura 5 é possível notar que do total de 9 alunos, 8 optaram pela opção "Aulas no laboratório de Informática" quando questionados sobre qual a forma mais interessante de aprender o conteúdo. 


\section{Em qual siuação você achou mais interessante aprender o conteúdo de frações?}

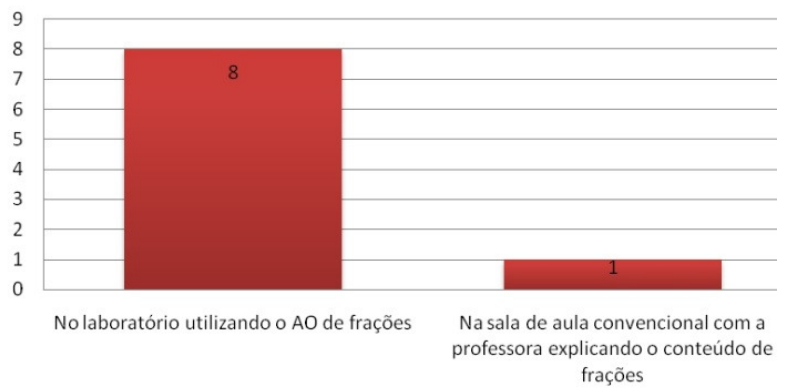

Figura 5: Gráfico de satisfação do usuário a aulas em laboratório

Outra questão pertinente a pesquisa destaca quais telas do OA despertaram maior interesses nos alunos, as opções "Atividades" e "Todas" foram as mais escolhidas, entretanto outras telas também foram alternativas escolhidas, como pode ser observado na Tabela 1.

Tabela 1: Telas com maior interesse do OA

\begin{tabular}{|c|c|}
\hline $\begin{array}{c}\text { Quais telas do OA foram } \\
\text { mais interessantes? }\end{array}$ & $\begin{array}{c}\text { Quantidades de vezes } \\
\text { que a alternativa foi } \\
\text { marcada }\end{array}$ \\
\hline $\begin{array}{c}\text { O vovô explicando o conte- } \\
\text { údo }\end{array}$ & 2 \\
\hline $\begin{array}{c}\text { Inserindo ingredientes para } \\
\text { fazer o bolo de laranja }\end{array}$ & 2 \\
\hline $\begin{array}{c}\text { Balões de pensamento do } \\
\text { Pedro contando as pizzas. }\end{array}$ & 1 \\
\hline $\begin{array}{c}\text { Frações Próprias, impróprias } \\
\text { e aparentes }\end{array}$ & 1 \\
\hline Números Mistos & 2 \\
\hline Leitura das frações & 4 \\
\hline Frações decimais & 0 \\
\hline Atividades & 4 \\
\hline Todas & 4 \\
\hline
\end{tabular}

Na tabela 1 é possível observar que os alunos optaram por duas telas de maior interesse, sendo elas "Todas" (Figura 6) e "Atividades" (Figura 7), o que apresentou um contentamento geral por utilizar o OA "Frações", já que a opção "Todas" foi marcada 4 vezes em um total de 9 alunos.

$E$

\section{Frações}
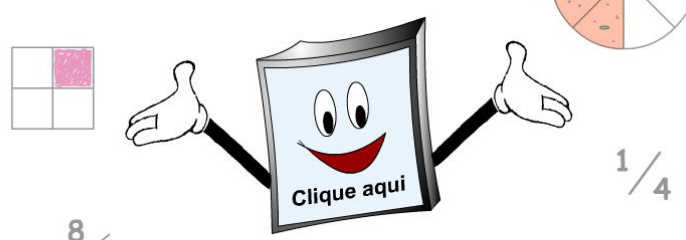

13

Objetos de Aprendizagem by GIED é licenciado pela Creative Commons Atribuição - Uso Não-Comercial Vedada a Criação de Obras Derivadas 2.5 Brasil License. $\odot 2009$ Gied

Figura 6: Tela inicial do OA representando a tela "Todas"

A opção atividades, representada na Figura 7, também foi marcada 4 vezes em um total de 9 alunos, sendo a segunda opção mais escolhida, empatando com a opção "Todas".

E GIED Grupo de Informática Educativa

\section{Atividades}

1. Camila ganhou $R \$ 50,00$ de seu pai para comprar um vestido, mas ela só gastou $1 / 2$ do dinheiro para comprá-lo. Quanto Camila gastou?

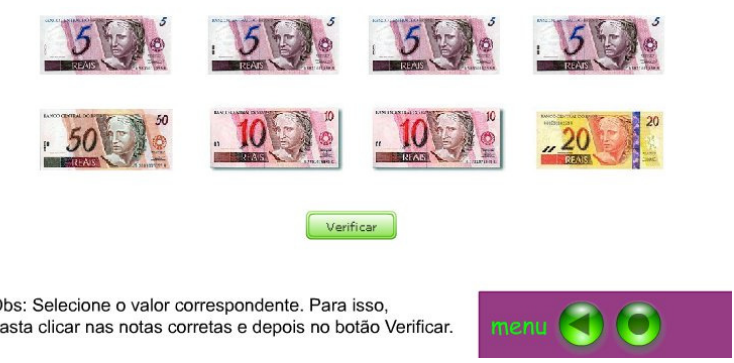

Figura 7: Tela da atividade 1 representando "Atividades"

Já a Figura 8 mostra as atividades escolhidas como mais interessantes pelos alunos. Desta forma, é possível 
notar que existe coerência entre os dados apresentados na Tabela 1 e as tabulações obtidas na Figura 8.

\section{Quais atividades você teve maior interesse}

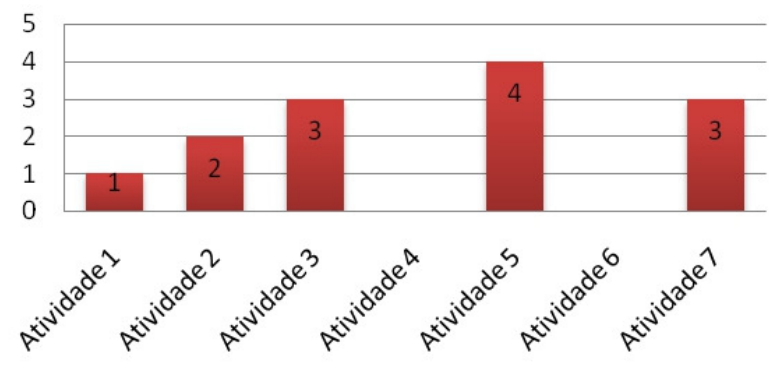

Figura 8: Atividades com maiores interesses

Do total de 9 alunos, 4 escolheram a atividade 5 como a mais interessante, $\mathrm{O}$ exercício 5 apresenta um caçapalavras no qual os alunos devem encontrar a leitura da fração em um emaranhado de palavras disposto na tela do computado (Figura 9).

O questionário aplicado a esses alunos foi desenvolvido com base no Objeto de Aprendizagem "Frações", com a finalidade de testar a interação, satisfação e motivação do usuário ao utilizar o OA.

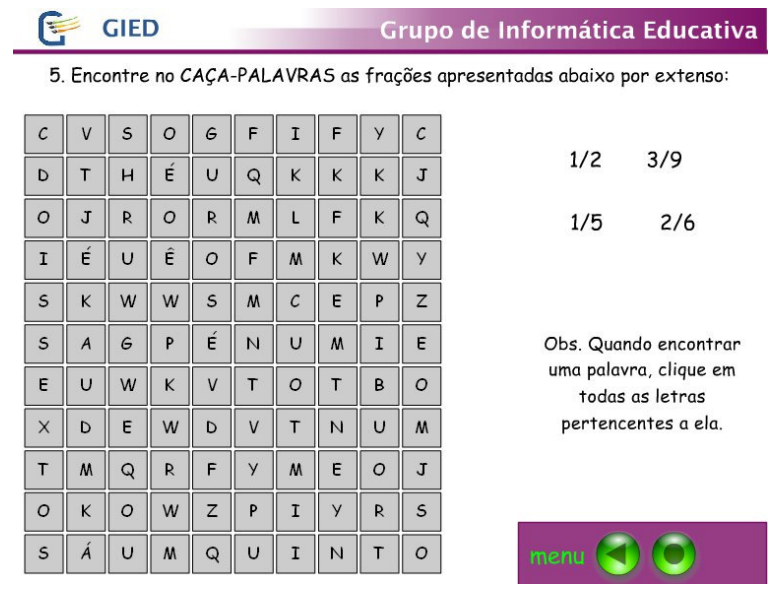

Figura 9: Atividade 5, escolhida como a mais interessante

Ao final contabilizou-se 5 aplicações de OAs em 4 turmas distintas da EJA, desse total, 3 abordaram conteúdos escolares e 2 utilizaram OAs de inclusão digital. $\mathrm{O}$ total de alunos por aplicação pode ser observado na Figura 10 .

\section{Total de alunos por aplicação}

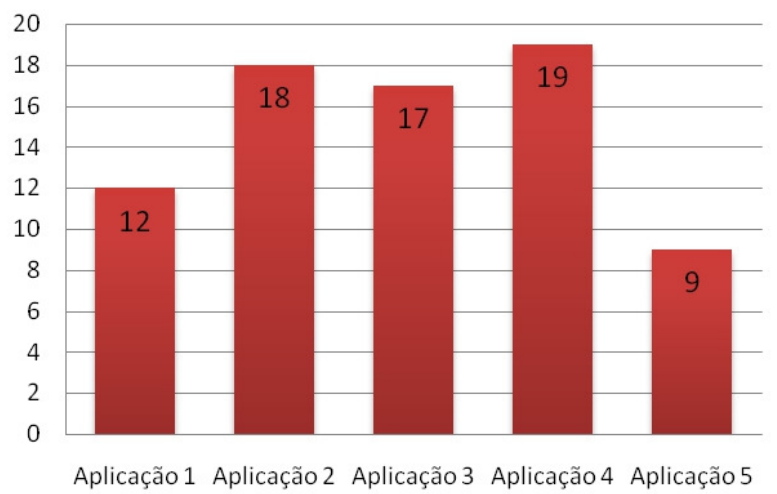

Figura 10: Total de alunos por aplicação de OA

De acordo com a Figura 11, foram realizadas 5 aplicações distintas, na primeira delas, 12 alunos utilizaram o Objeto de Aprendizagem "Adição e Subtração" que aborda conteúdos sobre estas duas operações fundamentais da matemática.

$\mathrm{Na}$ segunda aplicação, 18 alunos utilizaram o OA "Atmosfera" que tem como objetivo explicar a composição do ar e as camadas da atmosfera.

Na terceira e quarta aplicações, 17 e 19 alunos respectivamente utilizaram o OA "Introdução a Informática: Mouse", no qual aborda conteúdos de informática básica, tendo como principal objetivo ensinar o aluno a manusear corretamente o mouse.

Já na quinta aplicação, 9 alunos utilizaram o OA "Frações", esse Objeto de Aprendizagem apresenta conceitos introdutórios sobre medidas inexatas, também chamadas de frações. 


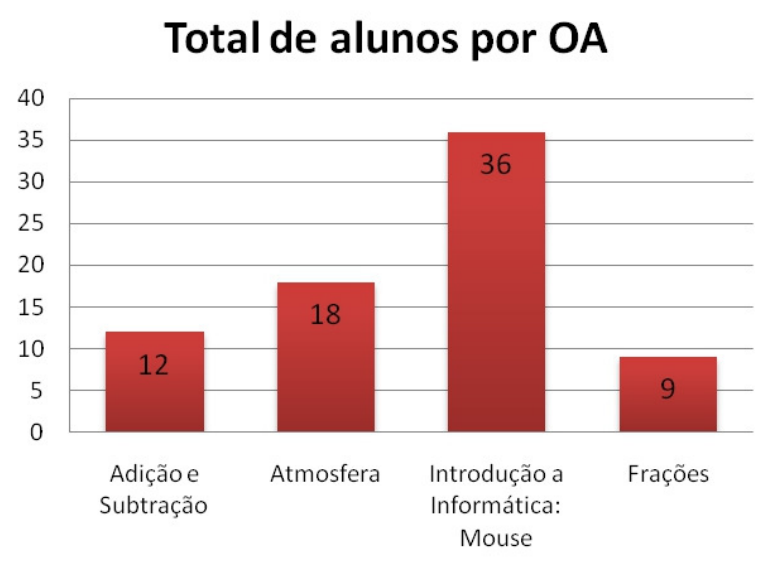

Figura 11: Total de alunos por $\mathrm{OA}$

Buscando quantificar a satisfação dos 36 alunos em aprender os conteúdos utilizando o OA "Introdução a Informática: Mouse", foi aplicada a seguinte pergunta: "O conteúdo sobre mouse foi bem explicado?", esse questionamento foi coletado ao final das 2 aplicações de inclusão digital, resultando no Figura 12.

\section{O conteúdo sobre mouse foi bem explicado?}

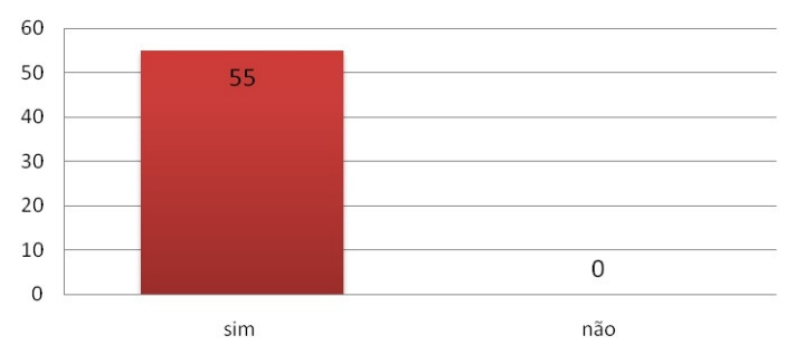

Figura 12: Satisfação do aluno quanto ao conteúdo do OA de Mouse

Observa-se que o grau de satisfação na explicação apresentada pelo Objeto de Aprendizagem de conteúdo de mouse foi positivo, pois do total de 55 alunos, 55 responderam que "Sim, o conteúdo sobre mouse foi bem explicado".

A mesma pergunta foi abordada no questionário da aplicação do OA "Frações", através da seguinte pergunta: "O conteúdo sobre frações foi bem explicado?", pode-se observar no Figura 13 que de um total de 9 alunos, 9 responderam estarem satisfeitos com a explicação do conteúdo.

\section{O conteúdo sobre frações foi bem explicado?}

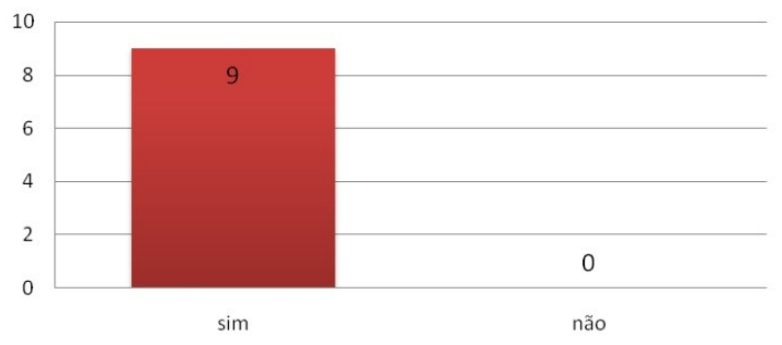

Figura 13: Satisfação do aluno quanto ao conteúdo do OA de Frações

Nas Figuras 12 e 13 é possível observar que $100 \%$ dos alunos responderam positivamente a pergunta, afirmando que os conteúdos dos OAs foram bem explanados.

Houve também as observações realizadas durante as aplicações dos OAs relatadas pelos estagiários, destacando-se na aplicação do Objeto de Aprendizagem "Atmosfera" inúmeros benefícios para a aprendizagem, como a demonstração de fenômenos físicos e químicos da natureza, o que não seria possível demonstrar ao aluno no mundo real, mas apresentado com maior facilidade no mundo virtual.

Como resultado principal, foi possível observar que a utilização de OAs como ferramenta para o apoio ao ensino trouxe um maior interesse e participação do aluno. Poder estudar o conteúdo e ver resultados de sua utilização virtualmente ocasionou uma maior efetividade na aprendizagem e na motivação afirmando assim a reutilização de OAs, ou seja, possibilitando sua em turmas distintas as focadas no seu desenvolvimento.

\section{Considerações Finais}

A presença constante dos computadores no âmbito social inclui essa ferramenta em vários espaços, como por exemplo, na educação, por isso não se pode ignorar o potencial pedagógico do computador no processo de ensino-aprendizagem.

Ressaltando assim a importância do uso de softwares educacionais para o auxilio no processo de ensinoaprendizagem.

Levando em consideração que um Objeto de Aprendizagem tem como característica a reutilização, a aplicação dos OAs em modalidades distintas do foco de desenvolvimento afirmou essa funcionalidade.

A utilização dos Objetos de Aprendizagem para a modalidade EJA destacou inúmeros benefícios, como a mo- 
tivação em estudar o conteúdo apresentado devido ao fato desses possibilitarem o uso de recursos visuais e verificações em tempo real, fatores que instigam a motivação do aluno em aprender.

De modo geral, as aulas no laboratório de informática mediadas por Objetos de Aprendizagem foram satisfatórias e aumentaram a motivação dos alunos em conhecerem os conteúdos apresentados. Isso se deve ao fato da utilização de contextos multimídias no OA, tais como: imagens, vídeos, falas e animações, como se pode observar em uma das respostas apresentadas por uma aluna da EJA quando indagada pela seguinte questão "Em qual situação você achou mais interessante aprender o conteúdo de frações, por quê?", respondendo "No laboratório de informática utilizando o $\mathrm{OA}$ de frações, porque da para acompanhar a explicação com figuras", a partir dessa resposta observou-se o fator multimídia como um item importante para a motivação do aluno na aprendizagem.

Deve-se também considerar o fato de que a utilização do computador ajuda não só no processo de aprendizagem de conteúdos escolares, mas também a capacitar o indivíduo para o mercado de trabalho. Mostrando assim, mais uma vez, a importância da informática na educação para alunos da EJA.

Tendo como base os resultados obtidos, conclui-se que a utilização de Objetos de Aprendizagem no âmbito da educação pode favorecer o processo de ensinoaprendizagem, auxiliando o professor a tornar a aula mais dinâmica. Por conseguinte, a aprendizagem mediada por softwares educacionais pode auxiliado de maneira satisfatória no ensino, tanto de conteúdos escolares, quanto conteúdos de inclusão social. É importante ressaltar que este trabalhou contribuiu para verificação da reutilização de objetos de aprendizagem, bem como para apoiar e fomentar a inserção da informática na educação de jovens e adultos.

\section{Referências}

[1] J. A. Valente. Computadores e Conhecimento: repensando a educação. Por que o computador na educação. Gráfica central da Unicamp, Campinas, São Paulo. 1993.

[2] IEEE. Draft Standard for Learning Object Metadata. New York: Institute of Electrical and Electronics Engineers. 2002. Disponível em: $<$ http://ltsc.ieee.org/wg12/files/LOM_1484_12 1_v1_Final_Draft.pdf $>$. Acesso em 13 nov. 2010 .
[3] Brasil. Secretaria de Educação Fundamental. Parâmetros curriculares nacionais. Brasília: MEC/SEF, 1997. p. 142.

[4] PROGRAMA NACIONAL DE TECNOLOGIA EDUCACIONAL - PROINFO. Disponível em:

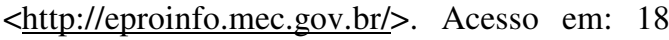
nov. 2010.

[5] REDE INTERNACIONAL VIRTUAL DE EDUCAÇÃO - RIVED. Disponível em: $<$ http://rived.mec.gov.br/>. Acesso em: 18 nov. 2010.

[6] UM COMPUTADOR POR ALUNO - UCA. Disponível em: <http://www.uca.gov.br/ institucional/>. Acesso em: 18 nov. 2010.

[7] Banco Internacional de Objetos Educacionais. Disponível em: <http://objetoseducacionais2. mec.gov.br/>. Acessado em: 16 dez. 2011

[8] S. P. Lopes, L. S. Souza. EJA: Uma educação possível ou mera utopia? Cereja: Revista Selva, São Paulo, 2004.

[9] N. Alves. Múltiplas Leituras sobre a LDB, Editora Arte e Ciência, Rio de Janeiro, 2001.

[10] INSTITUTO BRASILEIRO DE GEOGRAFIA E ESTATÍSTICA - IBGE. Tendências Demográficas. Disponível em:

$<$ http://www.ibge.gov.br/home/estatistica/popul acao/tendencia_demografica/tabela23.shtm>.

Acesso em: 17 nov. 2010.

[11] S. Haddad. Estado e educação de adultos. Tese de Doutorado. Faculdade de Educação, Universidade de São Paulo. São Paulo, 1991.

[12] UNESCO. Relatório sobre a educação. 1979. Disponível em: < http://www.unesco.org/new/ en/unesco/>. Acesso em: 25 nov. 2010.

[13] Brasil. Parecer CNE/CEB no 36/2004, de 7 de dezembro de 2004. Conselho Nacional de Educação, Brasília, Distrito Federal, P 29, 5 de março de 2006.

[14] M. K. Oliveira. Jovens e Adultos como sujeitos de conhecimento e aprendizagem, XXII Reunião Anual da ANPED, Caxambu, Minas Gerais. 1999.

[15] H. I. Martins, L. A. Carvalho, L. Ferreira, M. S. Calháu, M. L. T. Benício. Reflexões sobre a Migração da Prática Educativa com Jovens e Adultos para Sistemas Informatizado. Cadernos do IME: Série Informática, vol. 13, Dezembro 2002 . 
[16] PROGRAMA DE FORMAÇÃO DE PROFISSIONAIS DE NÍVEL TÉCNICO PARA A ÁREA DE SAÚDO NO ESTADO DE SÃO PAULO - TECSAUDE. EJA - Educação de Jovens e Adultos. Disponível em:

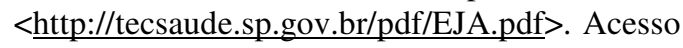
em: 18 nov. 2010.

[17] V. F. Santos, J. S. Veiga. O uso de softwares no ensino de funções quadráticas em um projeto educacional de jovens e adultos. IX ENEM Encontro Nacional de Educação Matemática, Minas Gerais, 2007.

[18] V. G. Bovo. O Uso do Computador na Educação de Jovens e Adultos. Revista PEC, Curitiba: v.2, 2002, p. 105-112.

[19] A. A. Fernandes, A. C. Souza, A. Chagas, A. D. Lucena, G. W. Moreschi, G. Scarton, J. H. Santos, M. Zanotto. Ler e escrever com histórias do cotidiano. Cascavel, Paraná. 2007.

[20] P. Freire. A importância do ato de ler. 45. Editora São Paulo, Cortez, 2003.

[21] Hamburgo. Confintea. Declaração de Hamburgo. Agenda para o Futuro. Brasília, SESI/UNESCO, 1999.

[22] J. M. Morgan. 2000. Um novo educador para uma nova era. Disponível em $<$ http://www.pucpr.br/institutos/sinep/pales_jm. $\underline{\mathrm{htm}}>$. Acessado 13 nov. 2010.

[23] V. Silva. Informática educacional repensando o uso dos computadores nas escolas de educação infantil e ensino fundamental. Disponível em:

$<$ http://biblioteca.universia.net/html_bura/ficha/ params/id/595861.html >. Acesso em: 13 nov. 2010.

[24] S. F. Tajra. Informática na Educação. São Paulo. Érica, 2000.

[25] R. L. Sampaio, A. C. Souza. Objetos Digitais de Aprendizagem: Uma ferramenta auxiliar no processo de ensino-aprendizagem da disciplina Informática Básica. João Pessoa: Artigo apresentado no II Congresso de Pesquisa e Inovação da Rede Norte Nordeste de Educação Tecnológica. 2007.

[26] R. F. Passarini. Objetos de aprendizagem: protótipo para módulo de ambiente de treinamento online. Dissertação de Mestrado, Universidade Federal de Santa Catarina, Florianópolis, 2003.
[27] D. A. Wiley. 2001. The Instructional Use of Learning Objects: Online Version. Disponível em: <http://reusability.org/read>. Acesso em: 08 nov. 2010.

[28] J. Muzio, T. Heins, R. Mundell. 2002. Experiences with Reusable Objects: From Theory to Practice. Victoria: CEDAR, Royal Roads University. Disponível em: <www.udutu.com/pdfs/eLearning-objects.pdf $>$ Acessado 19 nov. 2010.

[29] L. M. R. Tarouco, M. C. Fabre, F. R. Tamusiunas. Reusabilidade de Objetos Educacionais. Disponível em: $<$ http://www.nuted.ufrgs.br/oficinas/criacao/mar ie_reusabilidade.pdf $>$ Acesso em 27 de novembro de 2010.

[30] K. A. Oliveira, M. Amaral, V. F. Bartholo. Uma experiência para definição de storyboard em metodologia de desenvolvimento colaborativo de objetos de aprendizagem. Ciência e Cognição, v. 15, n. 1, 2010.

[31] C. B. Z. Vasconcelos, C. B. L. Lima, R. R. Magalhães. Avaliação de Objeto de Aprendizagem de Matemática por educadores de EJA - da Fundamentação pedagógica e de Conteúdo. Porto Alegre, 2010.

[32] W. A. Cybis. Ergonomia de Interfaces HomemComputador. Apostila para o Curso de PósGraduação em Engenharia de Produção, UFSC, 2000. Disponível em: <http://www.labiutil.inf. ufsc.br/apostila.htm>. Acesso em 27 de novembro de 2011.

[33] S. M. Schütz. Usabilidade do Ambiente de ELearning: estudo de caso da plataforma POLVO (UDESC). Dissertação de Mestrado, PPGCI, UFSC, Florianópolis, 2007.

[34] C. Dias. Usabilidade Na Web. Criando Portais Mais Acessíveis, Editora: Alta Books $2^{\mathrm{a}}$ Edição, Rio De Janeiro, 2007

[35] A. M. Medeiros. ISO 9241: uma proposta de utilização da Norma para avaliação do grau de satisfação de usuários de software. 1999. Dissertação (Mestrado em Engenharia de Produção) Programa de Pós-graduação em Engenharia de Produção, Universidade Federal de Santa Catarina, Florianópolis, 1999. 
Oliveira,K.A.; Amaral,M.A.; Domingos, G.R.

RBIE V.19 N.3 - 2011

64 